\title{
INCREASE OF OPERATING RELIABILITY OF THE TRAVEL WHEEL USING THE USE OF THE ELASTIC INSERTS
}

\author{
Nataliia Fidrovska \\ Department of Building and Road Cars \\ Kharkiv National Automobile and Highway University \\ 25 Yaroslava Mudrogo str., Kharkiv, Ukraine, 61002 \\ nfidrovskaya@ukr.net \\ Evgen Slepuzhnikov \\ Department of Special Chemistry and Chemical Technology \\ slepuzhnikov@nuczu.edu.ua \\ Oleksiy Larin \\ Department of Dynamics and Machine Strength ${ }^{2}$ \\ alexeya.larin@gmail.com \\ Ivan Varchenko \\ Department of Transport Machines and Ownership ${ }^{2}$ \\ kafptmio@gmail.com \\ Voloymyr Lipovyi \\ Department of Fire and Technological Safety of Facilities and Technologies ${ }^{1}$ \\ berestku@ukr.net \\ Kostiantyn Afanasenko \\ Department of Fire and Technogenic Safety of Facilities and Technologies ${ }^{1}$ \\ armfree0@gmail.com \\ Serhii Harbuz \\ Department of Fire and Technological Safety of Facilities and Technologies ${ }^{1}$ \\ sgarbuz65@gmail.com \\ ${ }^{1}$ National University of Civil Defence of Ukraine \\ 94 Chernyshevska str., Kharkiv, Ukraine, 61023 \\ ${ }^{2}$ National Technical University Kharkiv Polytechnic Institute" \\ 2 Kyrpychova str., Kharkiv, Ukraine, 61002
}

\footnotetext{
Abstract

The aim of research is to substantiate the rational design of the travel wheel based on the determination of the dynamic forces arising from the movement of the freight carriage and the crane bridge. The research methodology is based on analytical methods for studying dynamic forces in the mechanism of movement of the cargo carriage of an overhead crane. The obtained solution of the three-mass dynamic scheme of the movement of the freight carriage. To verify the theoretical data obtained, an experiment was carried out on an overhead crane with a lifting capacity of 5, span of $22.5 \mathrm{~m}$, lifting height of $8 \mathrm{~m}$, operating mode of $7 \mathrm{~K}$. The study of the vibration state was carried out on the crane beam in the middle of the span, on the axis of the driven wheel of the crane trolley with an elastic insert and on the axis of the drive wheel of the crane trolley of a conventional design.

Crane wheels are the fastest wearing parts of a crane. A decrease in their durability leads to an increase in repair costs and crane downtime. Therefore, increasing the durability of crane travel wheels is an urgent task of modern crane construction. All designs of travel wheels are quite rigid and do not perceive shocks and distortions arising from the deviation of the rail track from the recommended values and lead to significant wear of the flanges and rails.

The analysis of the obtained solutions showed that when using a travel wheel with an elastic insert, the dynamic factors during the movement of the freight carriage decrease. Dependences are obtained for determining the dynamic forces arising from
} 
the movement of the travel crane wheel, taking into account the rigidity of the elastic ring, which is installed in the travel wheel. The analysis of the regularities of the formation of vibration signs at different points of the overhead crane structure is carried out. The proposed design and calculation method for a travel wheel with an elastic insert improves its operational reliability.

Keywords: travel wheel, elastic insert, bridge crane, cargo trolley, dynamic loads of vibration acceleration.

DOI: $10.21303 / 2461-4262.2020 .001387$

\section{Introduction}

As practice shows, in some cases, typical crane equipment does not have the required service life [1]

Travel wheels of bridge-type cranes require special attention. Crane wheels are the fastest wearing parts of a crane. A decrease in their durability leads to an increase in repair costs and an increase in crane downtime, which for bridge cranes reaches up to $10-12 \%$ of the total downtime. The costs associated with the replacement and restoration of travel wheels account for $15-17 \%$ of the cost of repairing the entire crane.

The dynamic forces arising from the movement of cargo carts of cargo cranes are quite large and can't be ignored when designing cranes [2, 3]. They are especially manifested during the demolition of wheels and rails in the event of distortions on cranes $[4,5]$.

All designs of travel wheels are quite rigid and can't perceive those shocks and distortions that occur when the track deviates from the recommended values and leads to significant wear of the flanges and rails $[6,7]$.

Thus, improving the performance and increasing the operational reliability of crane travel wheels is a very urgent task of modern crane construction.

The dynamic models of the overhead crane are considered in [8]. The authors determined the linear vibrations of the model, which describes the vibration of the load and trolls during the movement of the crane, and estimated the frictional forces in the system. An assessment was made of the influence of the shift load during the action of the resistance forces during the movement of the crane. But the work does not consider the dynamic loads in the metal structure of the crane during movement.

The possibility of modernizing the mechanism of movement of the cargo carriage of an overhead crane by replacing a three-stage vertical cylindrical gearbox with two-stage and a separate gear transmission is considered in [9]. In this case, the travel wheel is directly mounted on the shaft of the bogie wheelset. The authors argue that such a block diagram will reduce energy losses and increase reliability. But at the same time, it was not investigated how much the dynamic loads change.

In work [10], a method is proposed for solving the problem of optimizing the movement of the cargo carriage of an overhead crane at a given distance, which gives a complete overcoming of uncontrollable mathematical oscillations of the load on a rope suspension. But the questions of the influence of the design of the movement mechanism remained unresolved.

The results of experimental studies of the appearance of lateral forces in an overhead crane, which change during movement, are given in [11]. It was found that the experimental values of the lateral forces are less than those determined theoretically. It would be advisable to consider wheels not only with a cylindrical profile, but also with a tapered one, which will provide lower lateral forces.

The optimal chemical composition of steel and the technology of technical processing for the travel wheels of mine trolleys are proposed in [12]. The authors claim that this should increase the wear resistance of the wheels, but a decrease in dynamic forces is not considered. It would be advisable to carry out theoretical studies that made it possible to more significantly assess the wear resistance of wheels.

The results of a numerical experiment using the hybrid approach of the finite element method and modeling the system dynamics of an overhead crane when lifting a load are presented in [13]. The purpose of the analysis was to study the effect of loading on the crane structure while simultaneously lifting the load and measuring vibrations in selected areas of the crane structure. The action of dynamic forces on the travel wheels is not considered, despite the fact that the operation 
of the movement mechanism can affect the dynamic processes in all crane mechanisms and even in the metal structure.

This gives grounds to assert that it is advisable to conduct a study to improve the operational reliability and durability of the travel wheel through the use of elastic inserts.

The aim of research is to substantiate the rational design of the travel wheel based on the determination of the dynamic forces arising from the movement of the freight carriage and the crane bridge.

To achieve the aim, the following objectives were set:

- to substantiate the design of a crane travel wheel with an elastic insert and to determine the dynamic factors during the operation of the mechanism of movement of a cargo trolley based on a three-mass dynamic system, taking into account the elasticity of an elastic insert;

- to conduct experimental studies of the formation of vibration signs that arise during the operation of the movement mechanism with travel wheels with elastic inserts and without inserts.

\section{Methodology for the experimental study of the movement of the freight carriage taking into account the elastic insert of the travel wheel}

The study of the crane travel wheel was carried out within the framework of the task of selecting and analyzing a more perfect wheel design, which will significantly increase its durability [14, 15]. The proposed improved design of a travel wheel with an elastic insert leads to a decrease in stresses in the wheel and wear of the travel gear, including the flanges [16]. The crane travel wheel is under the influence of static and dynamic loads [17]. Static forces are classified as vertical and horizontal. Vertical ones arise from the weight of the load and the load carriage for the mechanism of movement of the load carriage and the weight of the bridge and load for the mechanism of movement of the overhead crane. Horizontal forces, as a rule, are the forces of friction between the travel wheel and the rail [18]. Dynamic loads arise during transient processes, as well as when the wheels are skewed and passing through the joints of the rail track [19, 20].

The construction consists of several layers (Fig. 1), of which the outer layer is made of durable material, and the middle layer is a low-strength lightweight filler.

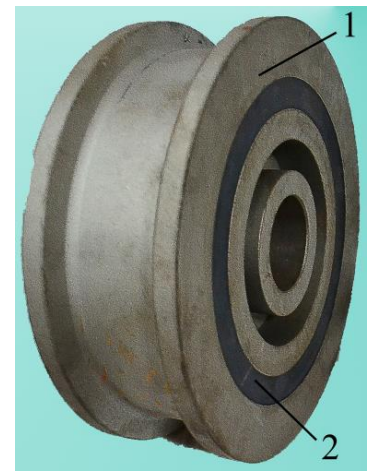

Fig. 1. Construction of crane travel wheel with elastic insert:

1 - outer layer of durable material, 2 - middle layer of lightweight filler

The filler is not only of reduced weight, but has high strength and rigidity, which is explained by the high value of the moment of inertia of the entire wall. Compared to a single-layer skin, the moment of inertia can be increased many tens of times.

Taking into account the flexible suspension of the load, let's have a three-mass scheme (Fig. 2).

The drive mechanism for the movement of the load trolley is located, as a rule, in the middle of the trolley path. The movement to the drive wheels is transmitted by a transmission shaft. In a detailed study of the dynamics of the movement mechanism, it is possible to use a design model with three masses and two elastic ties. It is possible to reduce all the parameters to the chassis of the bogie and the load. Then let's obtain a scheme of gradual movement (Fig. 2). 


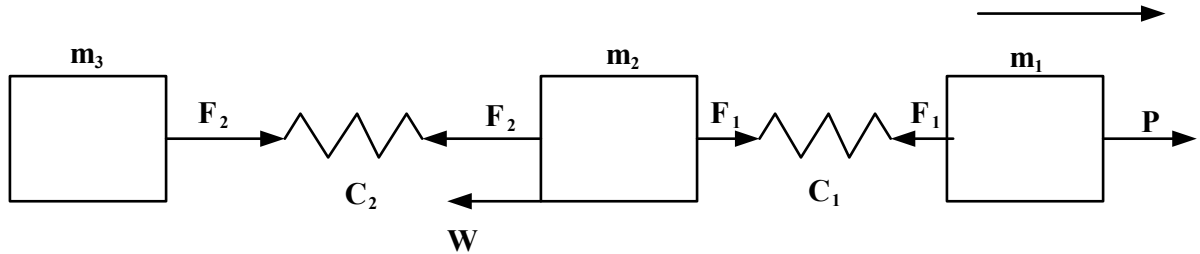

Fig. 2. Three-mass scheme of flexible load suspension: $m_{1}$ - mass of rotating parts (mass of the engine motor and other parts, mainly the motor clutch and brake pulley) $m_{2}-$ reduced mass of parts that move forward; $m_{3}$ - cargo weight; $\mathrm{C}_{1}$ - coefficient of stiffness of the low-speed transmission shaft; $C_{2}-$ stiffness of another elastic connection

Solve the system:

$$
\left\{\begin{array}{l}
m_{1} \ddot{x}_{1}=P-W-C_{1}\left(x_{1}-x_{2}\right), \\
m_{2} \ddot{x}_{2}=C_{1}\left(x_{1}-x_{2}\right)-C_{2}\left(x_{2}-x_{3}\right), \\
m_{3} \ddot{x}_{3}=C_{2}\left(x_{2}-x_{3}\right) .
\end{array}\right.
$$

After solving system (1), let's obtain the differential equation:

$$
\ddot{x}_{1}+a_{1} \ddot{x}_{1}+a_{2} x_{1}=a_{3},
$$

where

$$
\begin{gathered}
a_{1}=\frac{m_{1}}{2}\left(\frac{C_{1}}{m_{1}}+\frac{C_{1}+C_{2}}{m_{2}}\right)+\frac{m_{1}\left(C_{1}+C_{2}\right)}{2 m_{2}}, \\
a_{2}=\frac{C_{1}}{2}\left(\frac{2 C_{1}}{m_{1}}+\frac{2 C_{2}+C_{1}}{m_{2}}\right), \\
a_{3}=\frac{P-W}{2}\left(\frac{C_{1}+C_{2}}{m_{2}}-\frac{C_{1}}{m_{1}}\right) .
\end{gathered}
$$

The solution to equation (2) will be sought in the form:

$$
x_{1}=A_{1} \sin k_{1} t+A_{2} \cos k_{2} t+A_{3} \sin k_{3} t+A_{4} \cos k_{4} t+x_{1 \text { has }},
$$

where

$$
\begin{gathered}
x_{1 \text { hast }}=\frac{a_{3}}{a_{2}}, \\
k_{1,2,3,4}= \pm \sqrt{-\frac{a_{1}}{2}} \pm \sqrt{\frac{a_{1}^{2}}{4}-a_{2} .}
\end{gathered}
$$

Coefficients $A_{1}, A_{2}$ are determined using the initial conditions:

$$
\begin{aligned}
& x_{1}(0)=0, \\
& \dot{x}_{1}(0)=0, \\
& \ddot{x}_{1}(0)=0, \\
& x_{2}(0)=0 .
\end{aligned}
$$


Let's find the coefficient:

$$
\begin{gathered}
A_{3}=A_{4}=0, \\
A_{1}=-\frac{a_{3} k_{2}^{2}}{a_{2}\left(k_{2}^{2}-k_{1}^{2}\right)}, \\
A_{2}=\frac{a_{3} k_{1}^{2}}{a_{2}\left(k_{2}^{2}-k_{1}^{2}\right)} .
\end{gathered}
$$

After this equation (6) takes the form:

$$
x_{1}=\frac{a_{3}}{a_{2}}\left[1-\frac{1}{k_{2}^{2}-k_{1}^{2}}\left(k_{2}^{2} \cos k_{1} t-k_{1}^{2} \cos k_{2} t\right)\right] .
$$

The equations of motion for the second and third masses will be:

$$
\begin{gathered}
x_{2}=\frac{a_{3}}{a_{2}}\left\{1+\frac{1}{k_{2}^{2}-k_{1}^{2}}\left[k_{2}^{2}\left(\frac{m_{1} k_{1}^{2}}{C_{1}}-1\right) \cos k_{1} t-k_{1}^{2}\left(\frac{m_{1} k_{1}^{2}}{C_{1}}-1\right) \cos k_{2} t\right]\right\}-\frac{P-W}{C_{1}} . \\
x_{3}=\frac{a_{3}}{a_{2}}\left\{\begin{array}{l}
1-\frac{k_{2}^{2}}{k_{2}^{2}-k_{1}^{2}}\left[\begin{array}{l}
\left(1+\frac{C_{1}}{C_{2}}\right)\left(\frac{m_{1} k_{1}^{2}}{C_{1}}-1\right)- \\
-\frac{k_{1}^{2} m_{2}}{C_{2}}\left(\frac{m_{1} k_{1}^{2}}{C_{1}}-1\right)+\frac{C_{1}}{C_{2}}
\end{array}\right] \cos k_{1} t+ \\
+\frac{k_{1}^{2}}{k_{2}^{2}-k_{1}^{2}}\left[\begin{array}{l}
\frac{m_{2} k_{2}^{2}}{C_{1}}\left(\frac{m_{1} k_{2}^{2}}{C_{2}}+1\right)- \\
-\left(1+\frac{C_{1}}{C_{2}}\right)\left(\frac{m_{1} k_{2}^{2}}{C_{1}}-1\right)+\frac{C_{1}}{C_{2}}
\end{array}\right] \cos k_{2} t
\end{array}\right\}-\left(1+\frac{C_{1}}{C_{2}}\right) \frac{P-W}{C_{1}} .
\end{gathered}
$$

Let's find the efforts in elastic connections:

$$
F_{1}=P-\frac{a_{3} k_{1}^{2} k_{2}^{2}}{a_{2}\left(k_{2}^{2}-k_{1}^{2}\right)}\left(\cos k_{1} t-\cos k_{2} t\right) .
$$

A calculation was carried out for an overhead crane with a lifting capacity of 5 tons, a span of $22.5 \mathrm{~m}$, a lifting height of $8 \mathrm{~m}$, an operating mode of $7 \mathrm{~K}$.

According to the results of calculations, the dynamic coefficient of a standard travel wheel is 1.65 , and a travel wheel with an elastic insert is 1.1.

\section{Research results of the formation of vibration signs taking into account the elastic insert of the travel wheel}

To conduct an experimental study of vibration accelerations arising during the movement of the travel wheel, the Ultra-V-I complex was used. The general characteristics of the complex are summarized in Table 1.

The vibration measuring complex was located directly at the object of research - an overhead crane. The sensors were installed at the control points of the trolley and the crane and, using wires placed on the crane beam, were connected to an analog-to-digital converter, which, together with a computer, were located in the crane cabin (Fig. 3). The latter made it possible to exercise direct control over the operating modes of the crane (idling, lifting and moving loads of different weights at different speeds). 
Table 1

General characteristics of the "Ultra-V-I" complex

\begin{tabular}{cc}
\hline Parameter & Value \\
\hline Sensor type & ADXL250 \\
Measuring principle & Capacitive \\
Number of measurement axes & $2 / 3$ \\
Working range of amplitudes, $\mathrm{m} / \mathrm{s}^{2}$ & $0.2-40$ \\
Working frequency range, $\mathrm{Hz}$ & $0.1-400$ \\
Amplitude nonlinearity, $\%$ & 1 \\
Frequency response unevenness, $\%$ & 2 \\
Working temperature range, ${ }^{\circ} \mathrm{C}$ & $0-50$ \\
Number of ADC bits & 14 \\
Battery life, $\mathrm{h}$ & 2
\end{tabular}

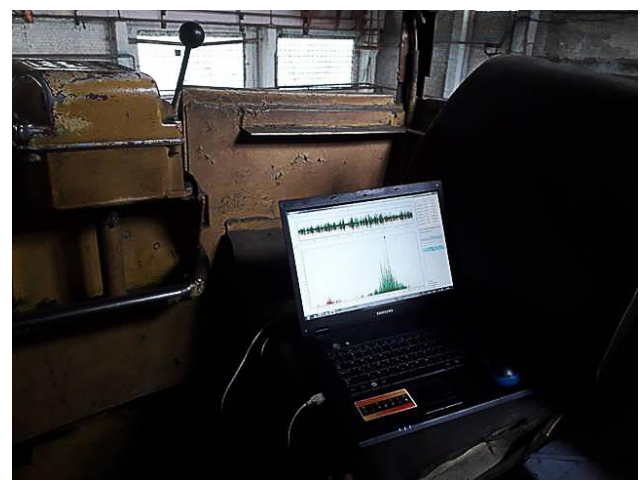

Fig. 3. Placement of the vibration measuring complex

The study of the vibration state was carried out in three control places:

- on the crane beam in the middle of the span;

- on the axis of the driven wheel of the crane trolley with an elastic insert (Fig. 4, a);

- on the axis of the drive wheel of the crane trolley of a conventional design (Fig. $4, \boldsymbol{b})$.

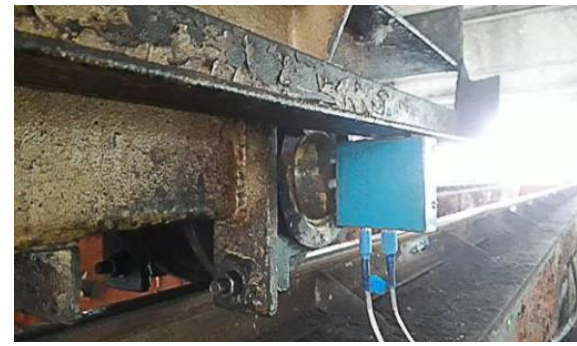

$a$

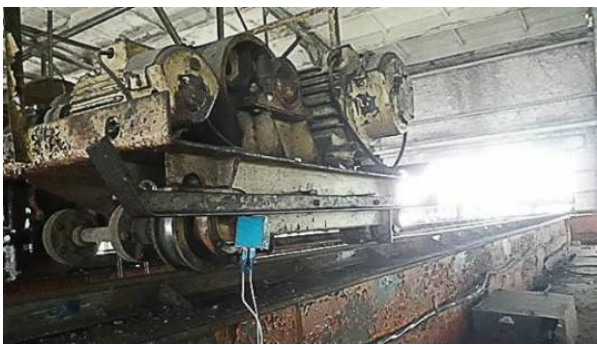

$b$

Fig. 4. Placement of acceleration sensors on the axle of the bogie wheels: $a$-driven wheel; $b$ - drive wheel

In accordance with the experimental research methodology, an analysis was made of the regularity of the formation of vibration signs at different points of the structure in the idling mode of the crane. That is, while the trolley is moving along the crane without load. At the same time, the modes of movement of the trolley with different speeds were considered.

Fig. 5 shows the recorded signals of vibration accelerations in the vertical direction on the rails and on the frame of the crane structure and their spectral densities. Spectral densities are given in a logarithmic scale along the frequency axis. 

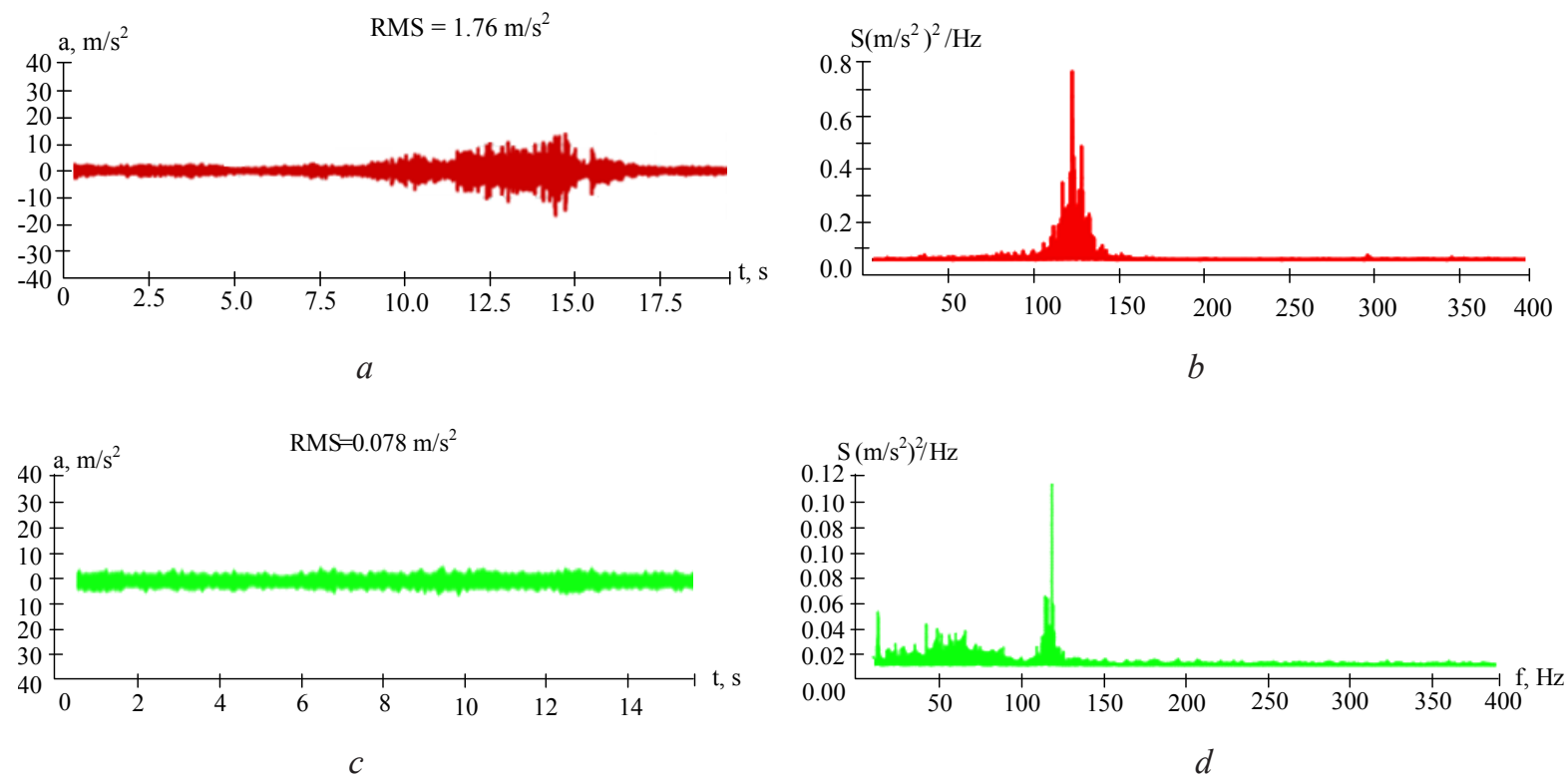

Fig. 5. Vibration acceleration in the vertical direction at idling of the bogie:

$a, b$ - vibration acceleration on the rails; $c, d$-vibration acceleration on the beam

On the recording of the vibration acceleration signal on the rails, it is possible to clearly see the time the trolley travels to the sensor location, when the signal level significantly increases.

Analysis of the spectral composition of these vibrations shows that high frequencies with a peak of $120 \mathrm{~Hz}$ prevail in the spectra of vibration accelerations. On the beam, there is a pronounced short-band noise in the range of $30-80 \mathrm{~Hz}$, the intensity of which increases with an increase in the speed of the trolley.

Fig. 6, 7 show the registered signals and their spectral analysis for vertical (Fig. 6) and axial (Fig. 7) vibrations on the axles of the driven and driven wheels. It should be noted that the driven wheel in this case is a modernized design and has elastic inserts.
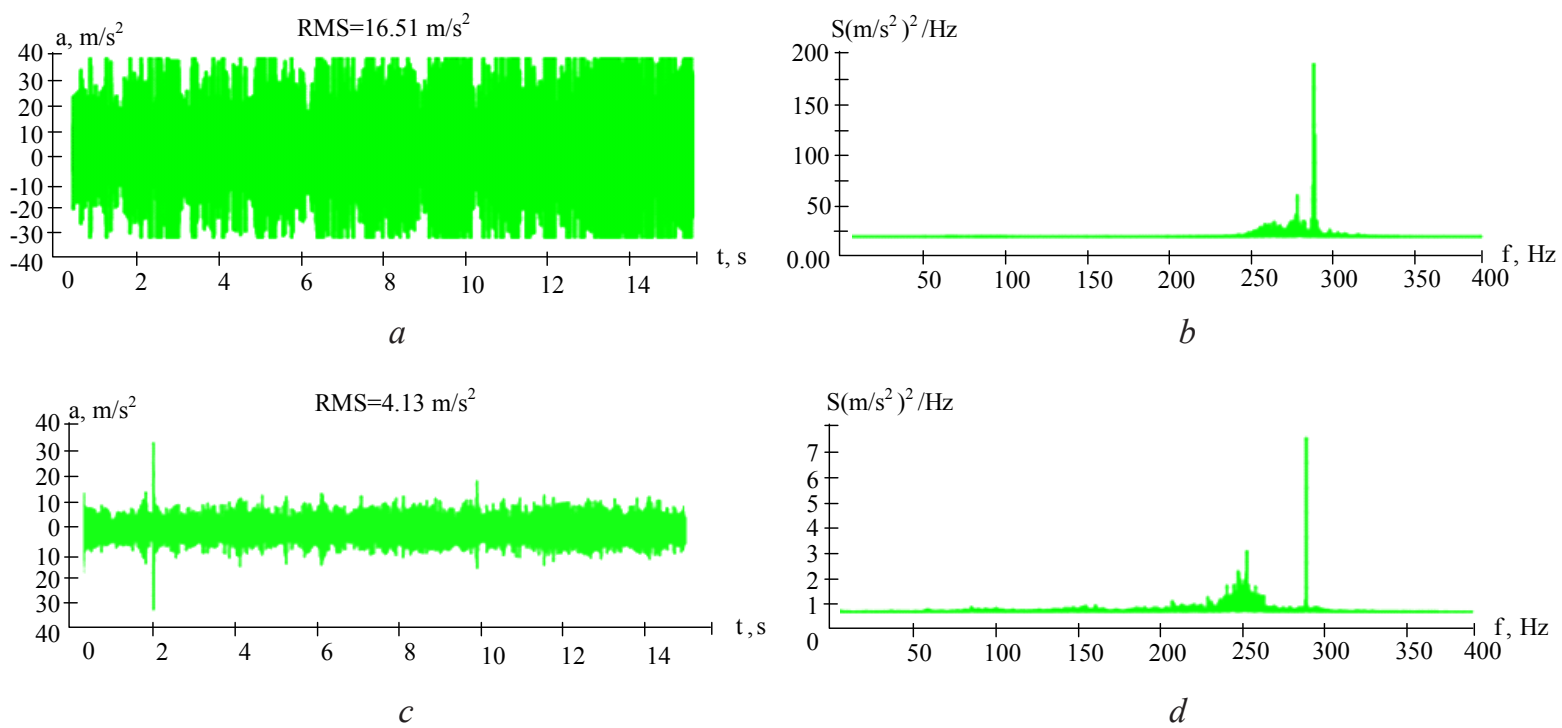

Fig. 6. Vibration acceleration in the vertical direction on the wheels during idling of the trolley at the first speed of movement: $a, b$-drive wheel; $c, d$-driven wheel

Vibration acceleration on wheels is expected to have a slightly higher level and a higher frequency spectrum than on rails or a crane. Almost harmonious vibrations with a frequency 
of $290 \mathrm{~Hz}$ are clearly expressed in the high-frequency spectrum. Vertical vibrations on the drive wheel axle also have a broadband component of 250-300 Hz.

The level of vibration accelerations in the vertical direction on the modernized driven wheel at idle is almost 4 times less than the level of vibration accelerations on the drive wheel of a conventional design. The situation is qualitatively the same at two recorded speeds. With an increase in the speed of movement, an increase in the level of vibrations is observed, as on the rails and in the beam.

Vibration in the axial direction (Fig. 7) is lower. The tendency to reduce vibration accelerations on the driven modernized wheel is also preserved here, but in quantitative terms, the reduction in vibrations is smaller - within $50 \%$.
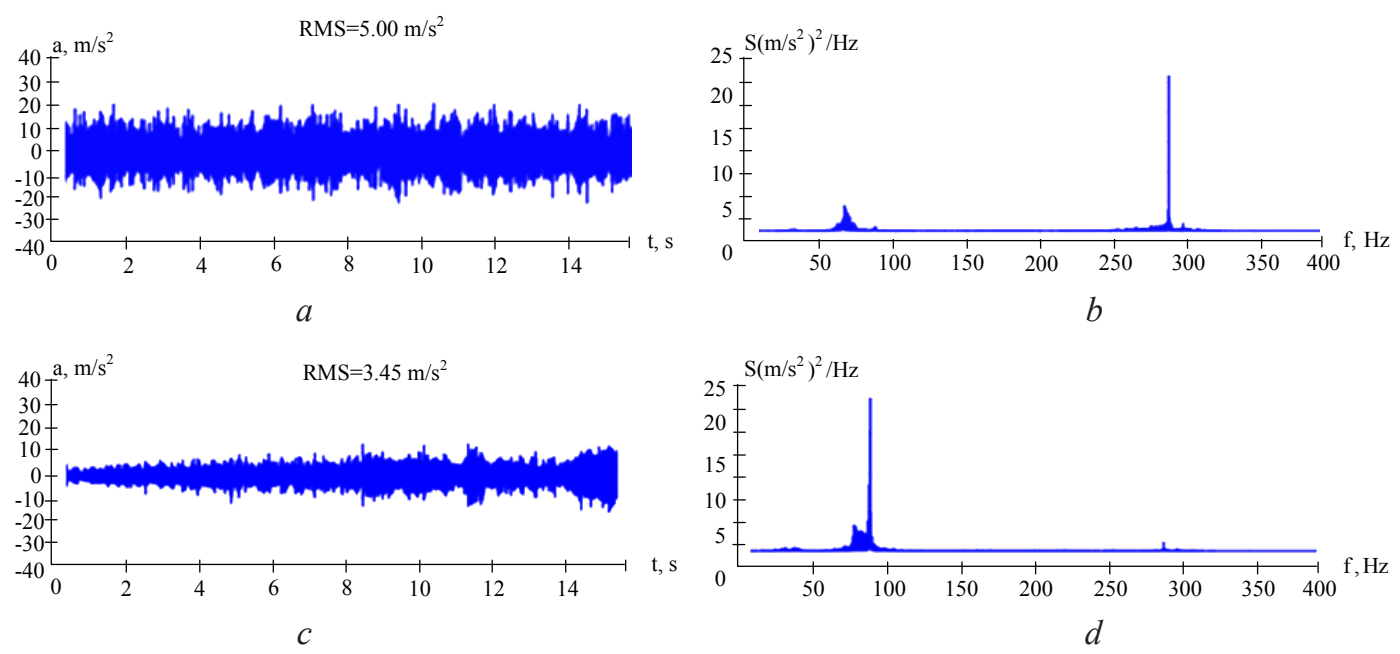

Fig. 7. Vibration acceleration in the axial direction on the wheels during idling of the bogie at the first speed of movement: $a, b$-drive wheel; $c, d$-driven wheel

Vibration studies were also carried out for the movement of a freight carriage, which moves loads of various weights.

The results of vibration tests when transporting a load of 2 tons on the wheel axle are shown in Fig. 8. Almost harmonious vibrations with a frequency of $290 \mathrm{~Hz}$, clearly expressed on the high-frequency spectrum. Vertical vibrations on the drive wheel axle also have a broadband component with a peak of $230 \mathrm{~Hz}$.
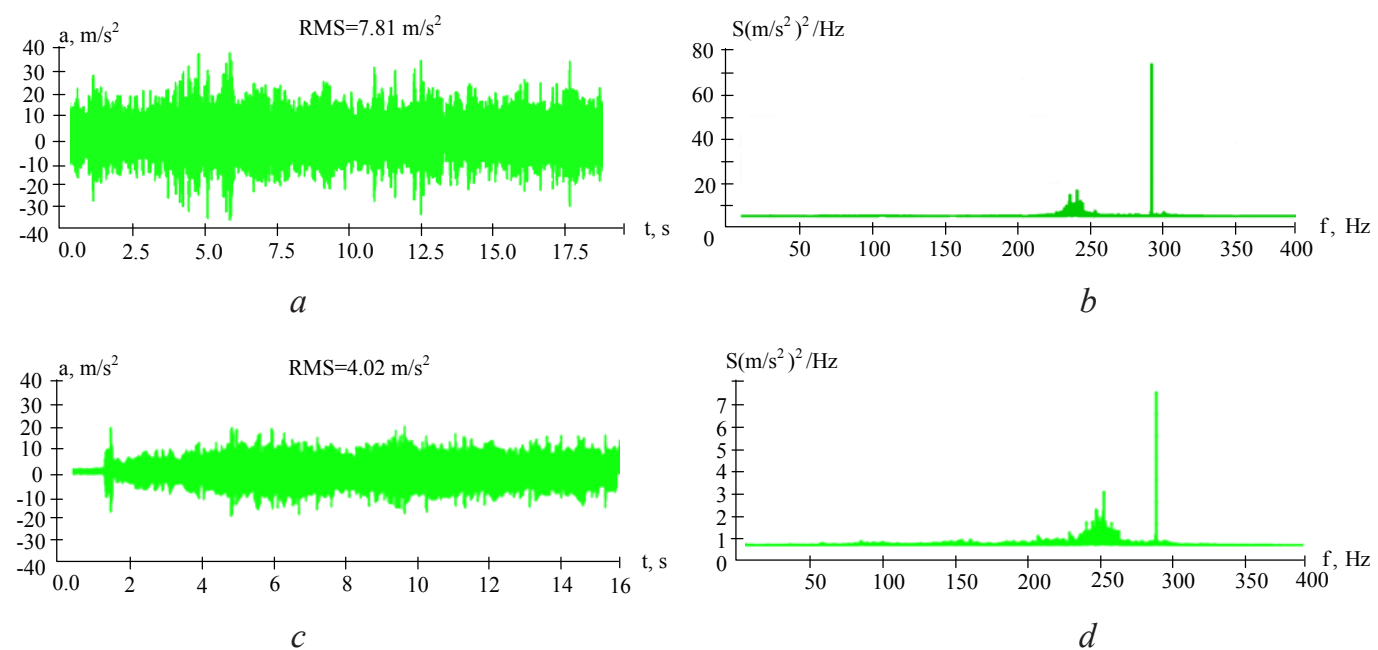

Fig. 8. Vibration acceleration in the vertical direction on wheels when transporting a load of 2 tons at the first speed of movement: $a, b$-drive wheel; $c, d$-driven wheel 
The level of vibration accelerations in the vertical direction on the modernized driven wheel at idle is almost 2 times less than the level of vibration accelerations on the drive wheel of a conventional design. The situation is qualitatively the same at two recorded speeds. With an increase in the speed of movement, an increase in the level of vibrations is observed.

Vibration in the axial direction (Fig. 9) is lower.
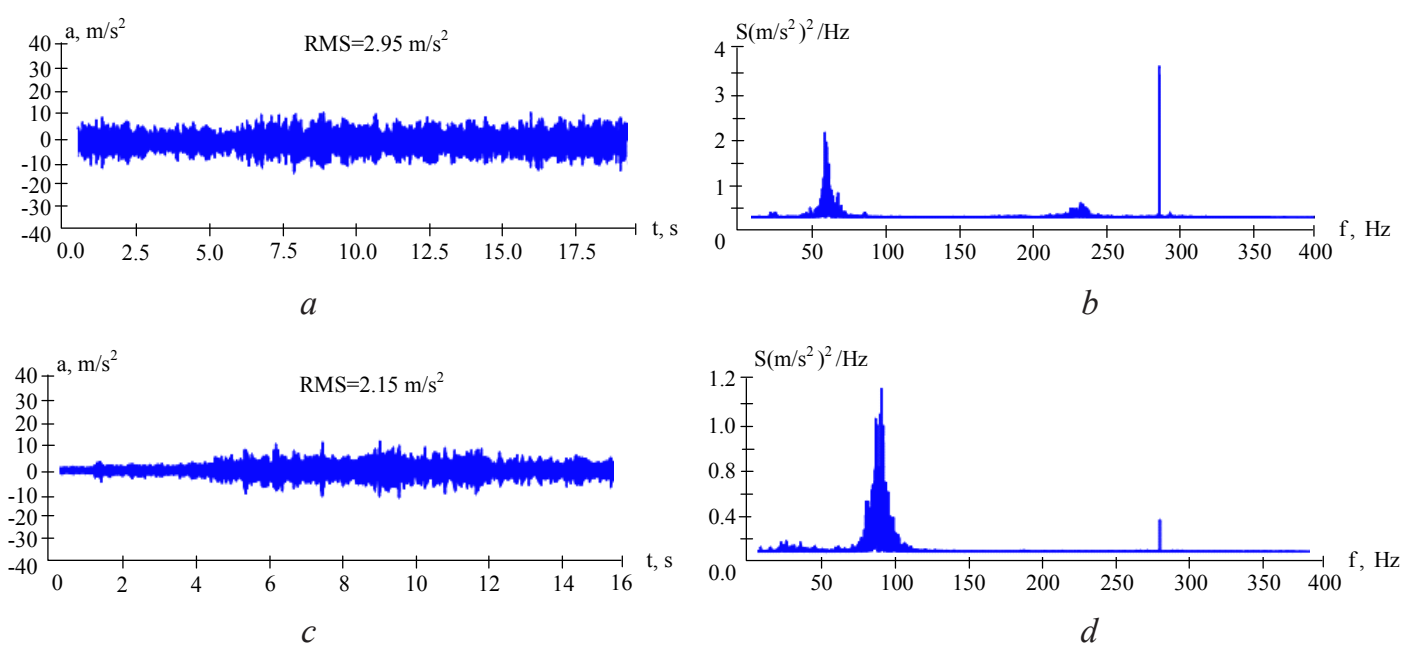

Fig. 9. Vibration acceleration in the axial direction on wheels when transporting a load of 2 tons at the first speed of movement: $a, b$-drive wheel, $c, d$-driven wheel

The tendency to reduce vibration accelerations on the driven modernized wheel is also preserved here, but in quantitative terms, vibration reduction is smaller -within about $70 \%$.

6. Discussion of the research results of the dynamics of the established movement of the freight carriage and the formation of vibration signs taking into account the elastic insert of the travel wheel

The substantiation of the design of a crane travel wheel with an elastic insert has been carried out. The dynamic factors are determined during the operation of the mechanism of movement of the freight carriage based on the three-mass dynamic system, taking into account the elasticity of the elastic insert.

Experimental studies of the formation of vibration signs that arise when the movement mechanism operates at different speeds, with travel wheels with elastic inserts and without inserts.

The generalized results of the RMS vibration acceleration in the vertical and axial directions on the modernized (with an elastic, rubber insert) and standard wheels (conventional design) are shown in Fig. 10, 11.

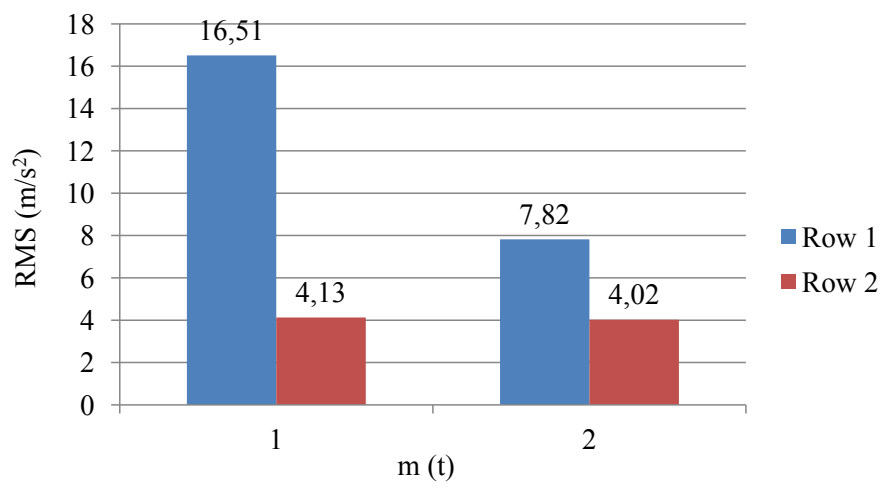

Fig. 10. RMS vibration acceleration in the vertical direction on wheels: row 1 - standard wheel; row 2 - upgraded wheel 


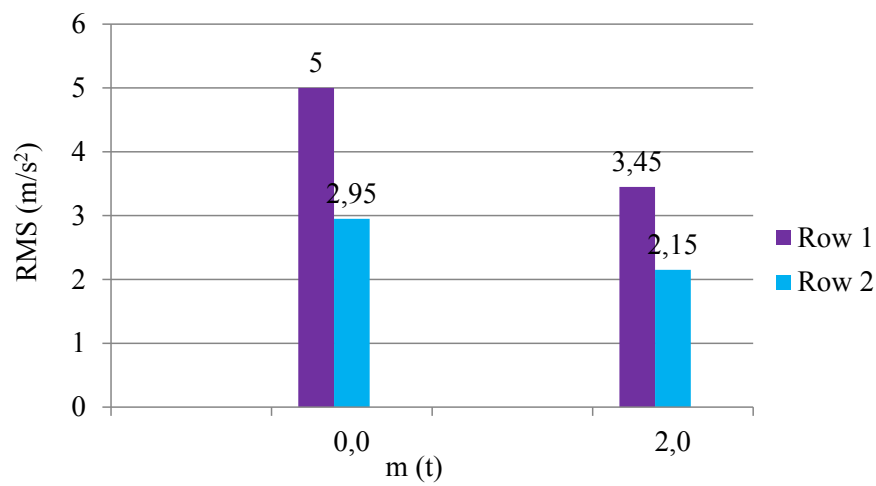

Fig. 11. RMS vibration acceleration in the axial direction on wheels: row 1 -standard wheel; row 2 - modernized wheel

The obtained results are explained by the fact that the proposed improved design of a travel wheel with an elastic insert leads to a decrease in the level of vibration accelerations in the vertical and axial directions on the modernized wheel, as well as wear of the travel gear, including the flanges. During the experiment, the modernized travel wheel was inspected after loading. Upon examination, no change in the elastic was found.

The article presents a new model of a travel wheel, which has significant advantages for its application in the mechanisms of movement of a crane cargo trolley and a crane. The calculations and experiments carried out have fully proved the feasibility of introducing such wheels on overhead cranes. The literature review showed that such a question has not yet been investigated by anyone.

In the future, it is necessary to conduct studies of the stress state of the elastic insert and the predicted durability of the travel wheel. It would also be advisable to use the strain gauge method during this pilot study.

\section{Conclusions}

Based on the results of determining the dynamic factors during the operation of the mechanism of movement of the freight carriage based on the three-mass dynamic system, taking into account the elasticity of the elastic insert, the dynamic coefficient was calculated. For a standard travel wheel, the dynamic coefficient is 1.65 , and for a travel wheel with an elastic insert 1.1.

The results of an experimental study of the formation of vibration signs arising in travel wheels show that the use of an elastic insert significantly reduces their level. So the ratio of vertical vibrations from modernization of wheels is $45 \%$, and the ratio of axial vibrations from modernization of wheels is $39 \%$.

\section{References}

[1] Haniszewski, T. (2017). Modeling the dynamics of cargo lifting process by overhead crane for dynamic overload factor estimation. Journal of Vibroengineering, 19 (1), 75-86. doi: https://doi.org/10.21595/jve.2016.17310

[2] Slepugnikov, E. (2016). Dynamic loadings at movement cargo cart of bridge crane. Engineering, 16, 34-37. Available at: http:// journals.uran.ua/index.php/2079-1747/article/view/57138/58294

[3] Romacevych, Y., Loveikin, V., Stekhno, O. (2019). Closed-loop optimal control of a system „trolley - payload”. UPB Scientific Bulletin, Series D: Mechanical Engineering, 81 (2), 3-12. Available at: https://www.scientificbulletin.upb.ro/rev_docs_arhiva/ rezaf5_410690.pdf

[4] Franchuk, V. P., Ziborov, K. A., Krivda, V. V., Fedoriachenko, S. O. (2017). On wheel rolling along the rail regime with longitudinal load. Naukovyi visnyk Natsionalnoho hirnychoho universytetu, 3, 62-67. Available at: http://nbuv.gov.ua/UJRN/ Nvngu_2017_3_12

[5] Ma, Y., Markine, V. L., Mashal, A. A., Ren, M. (2018). Effect of wheel-rail interface parameters on contact stability in explicit finite element analysis. Proceedings of the Institution of Mechanical Engineers, Part F: Journal of Rail and Rapid Transit, 232 (6), 1879-1894. doi: https://doi.org/10.1177/0954409718754941 
[6] Konowrocki, R., Chojnacki, A. (2019). Analysis of rail vehicles' operational reliability in the aspect of safety against derailment based on various methods of determining the assessment criterion. Eksploatacja i Niezawodnosc - Maintenance and Reliability, 22 (1), 73-85. doi: https://doi.org/10.17531/ein.2020.1.9

[7] Ma, Y., Markine, V. L., Mashal, A. A., Ren, M. (2018). Improving the performance of finite element simulations on the wheelrail interaction by using a coupling strategy. Proceedings of the Institution of Mechanical Engineers, Part F: Journal of Rail and Rapid Transit, 232 (6), 1741-1757. doi: https://oi.org/10.1177/0954409717745983

[8] Raksha, S. V., Anofriev, P. G., Bohomaz, V. M., Kuropiatnyk, O. S. (2019). Mathematical and s-models of cargo oscillations during movement of bridge crane. Naukovyi Visnyk Natsionalnoho Hirnychoho Universytetu, 2, 108-115. doi: https://doi.org/ $10.29202 / \mathrm{nvngu} / 2019-2 / 16$

[9] Artamonov, D. N., Petrov, A. M. (2017). Modernization of movement mechanism of crane bridge trolley. Molodoy issledovatel' Dona, 5 (8), 12-16. Available at: http://mid-journal.ru/upload/iblock/18e/2_artamonov_12_16.pdf

[10] Korytov, M. S. (2017). Bridge crane trolley movement in the anti-sway mode. Probl. Upr., 2, 10-16. Available at: http:// mi.mathnet.ru/eng/pu1015

[11] Zelić, A., Zuber, N., Šostakov, R. (2017). Experimental determination of lateral forces caused by bridge crane skewing during travelling. Eksploatacja i Niezawodnosc - Maintenance and Reliability, 20 (1), 90-99. doi: https://doi.org/10.17531/ein.2018.1.12

[12] Gankevich, V. F., Gryaznova, L. V., Lisnyak, A. G. (2012). Ways to enhance the reliability of wheel pairs of locomotive transport. Naukovyi Visnyk NHU, 5, 76-79. Available at: https://nvngu.in.ua/index.php/ru/component/jdownloads/finish/3505/565-2012-5-gankev/0

[13] Haniszewski, T. (2014). Hybrid analysis of vibration of the overhead travelling crane. Transport problems, 9 (2), 89-100. Available at: https://www.researchgate.net/publication/276235261_Hybrid_analysis_of_vibration_of_the_overhead_travelling_crane

[14] Fidrovska, N., Slepuzhnikov, E., Perevoznik, I. (2019). A contact problem solution with taking into account shear deformations. Science and Education a New Dimension, VII(193) (23), 80-81. doi: https://doi.org/10.31174/send-nt2019-193vii23-20

[15] Slepugnikov, Ye. D. (2016). Analysis of threeply tubular structure. Gornaya mehanika i mashinostroenie, 1, 62-65. Available at: http://repositsc.nuczu.edu.ua/handle/123456789/7460

[16] Fidrovska, N., Slepugnikov, E., Cherneshenko, A. (2015). Dynamic loadings before movement of motion wheel with rubber insertions. Mashinobuduvannya, 15, 87-91. Available at: http://repositsc.nuczu.edu.ua/handle/123456789/7457

[17] Molyneux-Berry, P., Davis, C., Bevan, A. (2014). The Influence of Wheel/Rail Contact Conditions on the Microstructure and Hardness of Railway Wheels. The Scientific World Journal, 2014, 1-16. doi: https://doi.org/10.1155/2014/209752

[18] Bogdevicius, M., Zygiene, R., Bureika, G., Dailydka, S. (2016). An analytical mathematical method for calculation of the dynamic wheel-rail impact force caused by wheel flat. Vehicle System Dynamics, 54 (5), 689-705. doi: https://doi.org/ 10.1080/00423114.2016.1153114

[19] Ren, Z., Iwnicki, S. D., Xie, G. (2011). A new method for determining wheel-rail multi-point contact. Vehicle System Dynamics, 49 (10), 1533-1551. doi: https://doi.org/10.1080/00423114.2010.539237

[20] Shabana, A. A., El-Ghandour, A. I., Zaazaa, K. E. (2011). Study of the effect of the spiral geometry on wheel/rail contact forces. Proceedings of the Institution of Mechanical Engineers, Part K: Journal of Multi-Body Dynamics, 225 (2), 111-125. doi: https://doi.org/10.1177/1464419311406626 